\title{
Interstitial pneumonitis in a castration- resistant prostate cancer patient receiving cabazitaxel after thoracic radiation therapy: a case report
}

\author{
Yoshinori Yanai, Takeo Kosaka ${ }^{*}$ (D, Hiroshi Hongo and Mototsugu Oya
}

\begin{abstract}
Background: Interstitial pneumonitis is a rare reaction in a previously irradiated area of pulmonary or thoracic lesion after treatment with anticancer drugs such as taxanes.

Case presentation: A 66-year-old man presented with a fever and dyspnea after treatment with cabazitaxel for castration-resistant prostate cancer. He was treated with an intravenous broad-spectrum antimicrobial agent, however he complained of dyspnea and had a pulse oximetric saturation of $80 \%$ while breathing room air. The patients had been treated for bone metastases with $37.5 \mathrm{~Gy}$ to the thoracic spine (Th 7) as a local radiotherapy. Radiological images showed pulmonary interstitial opacities in the irradiated field of the both lungs. The steroid pulse therapy was started. The patient's dyspnea disappeared and the interstitial opacities had also improved.
\end{abstract}

Conclusions: This report is a case of interstitial pneumonitis in a castration-resistant prostate cancer patient receiving cabazitaxel after thoracic radiation therapy.

Keywords: Cabazitaxel, Castration-resistant prostate cancer, Interstitial pneumonitis, Radiation recall pneumonitis, Thoracic radiotherapy

\section{Background}

Cabazitaxel is widely used for patients with castrationresistant prostate cancer. Local thoracic radiotherapy is also a common palliative radiation treatment. This report presents a case of interstitial pneumonitis after treatment with triggering agents such as taxanes, which is a rare reaction in a previously irradiated area of pulmonary or thoracic lesion [1].

\section{Case presentation}

A 66-year-old man was diagnosed with castration-resistant prostate cancer (CRPC) and treated with enzalutamide followed by six cycles of docetaxel chemotherapy. However, his serum prostate specific antigen level increased to $899 \mathrm{ng} / \mathrm{mL}$, so he was diagnosed as docetaxel resistant CRPC. Figure 1 shows bone metastases. The patient was

\footnotetext{
* Correspondence: takemduro@gmail.com; takemduro@keio.jp Department of Urology, Keio University School of Medicine, 35 Shinanomachi, Shinjuku-ku, Tokyo 160-0016, Japan
}

treated for bone metastases with $37.5 \mathrm{~Gy} / 15$ fr to the thoracic spine (Th 7) as a local radiotherapy from February 2016 to March 2016. The radiation induced only mild dermatitis as an adverse event. Moreover, internal fixation of the left femur was performed to prevent pathological fractures due to metastasis to the left femur on August 2016. He also received six cycles of intravenous injections of radium-223 $(50 \mathrm{kBq} / \mathrm{kg})$ once every 4 weeks from September 2016 to January 2017.

On admission in April 2017, the patient was started on cabazitaxel at $22.5 \mathrm{mg} / \mathrm{m}^{2}$ with proactive management of adverse events, including the use of a prophylactic long-acting granulocyte colony stimulating factor (G-CSF) and an oral empirical broad-spectrum antimicrobial agent (sitafloxacin hydrate, a new-generation, broad-spectrum oral fluoroquinolone that is very active against many Gram-positive, Gram-negative and anaerobic bacteria) to prevent febrile neutropenia. On day 10 , grade 4 neutropenia and febrile neutropenia were observed.

(C) The Author(s). 2019 Open Access This article is distributed under the terms of the Creative Commons Attribution 4.0 International License (http://creativecommons.org/licenses/by/4.0/), which permits unrestricted use, distribution, and 


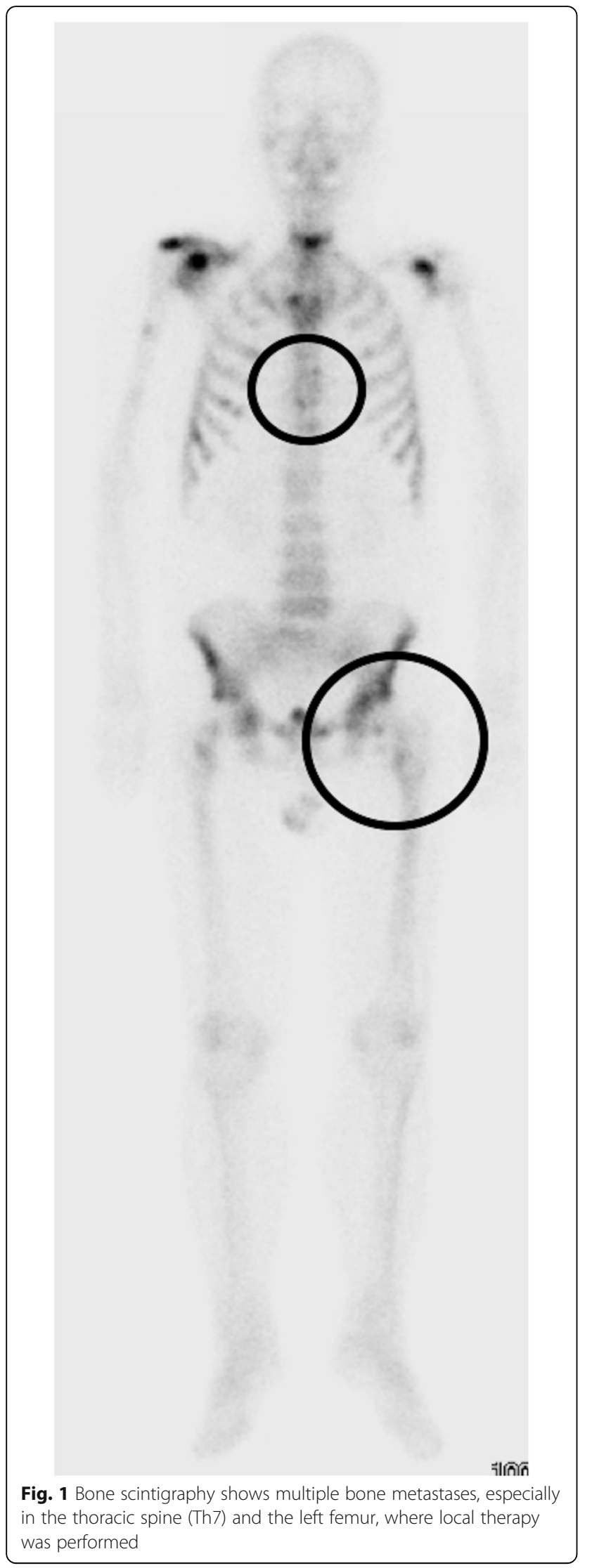

He was treated with an intravenous broad-spectrum antimicrobial agent (cefepime, a broad-spectrum cephalosporin with enhanced coverage against Gram-positive and Gramnegative bacteria), which resulted in cessation of the fever and increased neutrophil count, although sputum and blood cultures revealed negative. On day 18, he developed a secondary fever of $38^{\circ} \mathrm{C}$ again despite neutrophil count of $3000 / \mu \mathrm{L}$, so antimicrobial administration (cefepime) was restarted due to a suspected infection. Three days later, he complained of dyspnea and had a pulse oximetric saturation $\left(\mathrm{SpO}_{2}\right)$ of $80 \%$ while breathing room air. The serum Krebs von den Lungen-6 (KL-6) and surfactant protein (SP-D) levels were $744 \mathrm{U} / \mathrm{mL}$ and $147 \mathrm{ng} / \mathrm{mL}$ (normal ranges, $<500 \mathrm{U} / \mathrm{ml}$ and $<100 \mathrm{ng} / \mathrm{ml}$, respectively). The serum levels of procalcitonin, endotoxin concentration and (1,3)-beta-D-glucan were not elevated. Chest X-ray showed interstitial opacities indicative of inflammation in the irradiated field of the both lungs (Fig. 2a). Chest computed tomography (CT) showed interstitial lung disease with ground glass opacities in the irradiated field of both lungs (Fig. 2b). These characteristic image findings could have been associated with drug toxicity, due to the treatment of thoracic radiation therapy followed by cabazitaxel.

The intravenous steroid pulse therapy was started at a methylprednisolone of $1000 \mathrm{mg}$ a day for 3 days, followed by prednisolone at $1.0 \mathrm{mg} / \mathrm{kg}$ of body mass per day for a week. The patient improved and dyspnea disappeared. $\mathrm{SpO}_{2}$ showed $95 \%$ while breathing room air. The ground-glass opacities had also improved (Fig. 2c, d). The dosage of prednisolone was gradually reduced every week. The follow-up observation is still ongoing.

\section{Discussion and conclusions}

Cabazitaxel has yielded incremental extensions of survival for post-docetaxel patients. As Agarwal et al. mentioned, the success of cabazitaxel, following docetaxel, may warrant the continued evaluation of chemotherapeutic agents for metastatic CRPC (mCRPC) [2]. The common adverse events of cabazitaxel were diarrhea, fatigue, nausea, and neutropenia [3]. The most common clinically significant hematological grade 3 or higher adverse events of cabazitaxel were neutropenia (82\%) and the incidence of dyspnea of grade 3 or higher was less than $1 \%$ with cabazitaxel in the TROPIC trial [4]. Cabazitaxel is a tubulin-binding taxane that blocks mitosis in tumor cells and could cause other minor side effects. We previously reported hemorrhagic cystitis in a patient who was treated with cabazitaxel [5]. An interstitial lung disease associated with docetaxel and paclitaxel was reported previously, however in this report, cabazitaxel could also cause a pulmonary interstitial disease after radiotherapy.

In our patient, the dose-reduction of cabazitaxel at a dose of $22.5 \mathrm{mg} / \mathrm{m} 2$ was required due to his reduced 


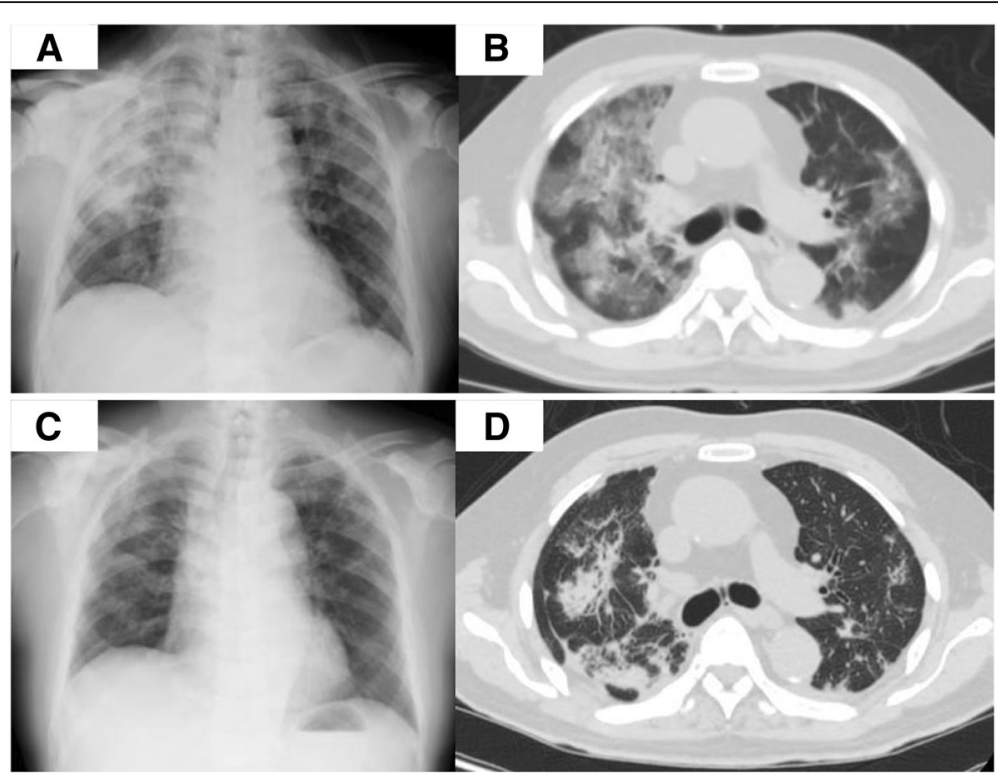

Fig. 2 a Chest X-ray findings before the steroid pulse therapy. b Chest computed tomography findings before the steroid pulse therapy. c Chest $\mathrm{X}$-ray findings after the steroid pulse therapy. $\mathbf{d}$ Chest computed tomography findings after the steroid pulse therapy

general condition. Prior treatment included docetaxel chemotherapy, enzalutamide, intravenous radium-223 and local radiotherapy. A full dose of cabazitaxel could induce severe adverse events in such a patient. A phase I cabazitaxel study in Japanese patients with mCRPC revealed the most frequent toxicities were neutropenia and febrile neutropenia, occurring at grade $\geq 3$ in 100 and $54.5 \%$ of patients, respectively, although prophylactic administration of G-CSF was not permitted at cycle 1 [6]. Cabazitaxel induced a high rate of grade $3 / 4$ neutropenia, which need to be proactively managed to avoid neutropenic complications. Di Lorenzo et al. revealed that prior cumulative dose was associated with reduced grade 3 to grade 4 neutropenia and anemia [7]. At our institute, all patients receive cabazitaxel at $20-25 \mathrm{mg} / \mathrm{m}^{2}$ administered intravenously on day 1 of each treatment cycle, together with prophylactic G-CSF. Of 41 patients with $\mathrm{mCRPC}$ treated with cabazitaxel in the previous retrospective study, grade $\geq 3$ neutropenia and febrile neutropenia occurred in 21 and (53.6\%) and 3 (6.8\%) patients, respectively, which is believed to be an improvement compared to the phase I cabazitaxel study in Japanese patients [3]. Moreover, internal fixation of the left femur was performed to prevent pathological fractures due to metastasis to the left femur. Therefore, after consulting with the patient, we decided to use antibiotics prophylactically.

When the secondary high fever occurred, a multipledrug-resistant bacterial infection was considered at first. However, CT image and laboratory tests did not indicate bacterial pneumonitis. They revealed drug induced interstitial lung disease, then a steroid therapy was started.
Some antitumor drugs are associated with a recall effect of pneumonitis after radiotherapy, however, the etiology and mechanism is unknown yet [1]. The diagnosis of radiation recall pneumonitis induced by chemotherapy is established based on a history of chemotherapy after thoracic radiotherapy, clinical presentation, and radiographic abnormality. This report is a case of interstitial pneumonitis in a castration-resistant prostate cancer patient receiving cabazitaxel after thoracic radiation therapy and may help guide the management of patients with dyspnea and fever treated with cabazitaxel and radiotherapy.

\section{Abbreviations}

CRPC: Castration-resistant prostate cancer; CT: Computed tomography; G-

CSF: Granulocyte colony stimulating factor; $\mathrm{SpO}_{2}$ : A pulse oximetric saturation

\section{Acknowledgements}

Not applicable.

\section{Authors' contributions}

YY and TK made substantial contributions to conception and design of the work. $\mathrm{HH}$ and $\mathrm{MO}$ made substantial contributions to the laboratory analysis and interpretation of data. YY and TK made substantial contributions to the acquisition of clinical data and their interpretation. YY and TK have been involved in drafting the manuscript. MO has been involved in critically revising the manuscript for important intellectual content. All authors read and approved the final manuscript.

\section{Funding}

None.

Availability of data and materials

All data generated or analyzed during this study are included in this published article.

Ethics approval and consent to participate Not applicable. 


\section{Consent for publication}

Written informed consent was obtained from the patient for publication of this case report.

\section{Competing interests}

The authors declare that they have no competing interests.

Received: 27 August 2018 Accepted: 16 July 2019

Published online: 22 July 2019

\section{References}

1. Ding X, Ji W, Li J, Zhang X, Wang L. Radiation recall pneumonitis induced by chemotherapy after thoracic radiotherapy for lung cancer. Radiat Oncol. 2011;6:24.

2. Agarwal N, Di Lorenzo G, Sonpavde G, Bellmunt J. New agents for prostate cancer. Ann Oncol. 2014;25:1700-9.

3. Kosaka T, Shinojima T, Morita S, Oya M. Prognostic significance of grade 3/4 neutropenia in Japanese prostate cancer patients treated with cabazitaxel. Cancer Sci. 2018;109:1570-5.

4. de Bono JS, Oudard S, Ozguroglu M. Prednisone plus cabazitaxel or mitoxantrone for metastatic castration-resistant prostate cancer progressing after docetaxel treatment: a randomised open-label trial. Lancet. 2010;376: 1147-54.

5. Kosaka T, Oya M. Hemorrhagic cystitis in a patient without a past history of radiation therapy who was treated with cabazitaxel for CRPC. Ann Oncol. 2015;26:2355-6.

6. Nozawa M, Mukai H, Takahashi S, Uemura H, Kosaka T, Onozawa Y, Miyazaki J, Suzuki K, Okihara K, Arai Y, Kamba T, Kato M, Nakai Y, Furuse H, Kume H, Ide H, Kitamura H, Yokomizo A, Kimura T, Tomita Y, Ohno K, Kakehi Y. Japanese phase I study of cabazitaxel in metastatic castration-resistant prostate cancer. Int J Clin Oncol. 2015;20:1026-34.

7. Di Lorenzo G, Bracarda S, Gasparro D, Gernone A, Messina C, Zagonel V, Puglia L, Bosso D, Dondi D, Sonpavde G, Lucarelli G, De Placido S, Buonerba C. Lack of cumulative toxicity associated with Cabazitaxel use in prostate Cancer. Medicine. 2016;95:e2299.

\section{Publisher's Note}

Springer Nature remains neutral with regard to jurisdictional claims in published maps and institutional affiliations.

Ready to submit your research? Choose BMC and benefit from:

- fast, convenient online submission

- thorough peer review by experienced researchers in your field

- rapid publication on acceptance

- support for research data, including large and complex data types

- gold Open Access which fosters wider collaboration and increased citations

- maximum visibility for your research: over $100 \mathrm{M}$ website views per year

At $\mathrm{BMC}$, research is always in progress.

Learn more biomedcentral.com/submissions 